\title{
CVD Diamond Coated Tungsten Carbide (WC) Tool Inserts
}

\author{
Ramakant Rana*, Lucky Krishnia**, R.S. Walia*** and Qasim Murtaza* \\ * Department of Mechanical Engineering, Delhi Technological University, Delhi, India \\ ** Amity Center of Nanotechnology, Amity University Haryana -122413, India \\ *** Department of Production and Industrial Engineering, Punjab Engineering College, Chandigarh, India \\ **Corresponding Author : luckykrishnia.research@gmail.com
}

\begin{abstract}
In this paper a self-developed polycrystalline diamond coating was done on tungsten carbide (WC) tool insets by using simple thermal chemical vapor deposition technique. The growth of these diamond films has been carried out at $\sim 900{ }^{\circ} \mathrm{C}$ temperature. The as-grown polycrystalline diamond films on the surface of tungsten carbide tool inserts have been characterized using Raman spectrometer and scanning electron microscope (SEM). The morphological studies reveal that the as-grown diamond films are of high crystalline quality. The as-grown diamond films possess compressive stress. The micro-hardness indentation test of the as-grown diamond films on WC tool inserts and bare have also been done and it has been found that the Vicker's hardness of the as-grown diamond WC tool inserts is found to be $1423.32 \mathrm{HV}$ which is $29 \%$ better than the un-coated tools.
\end{abstract}

Keywords: Tungsten carbide; Diamond coating; Wear; Friction; Tool inserts.

\section{INTRODUCTION}

In wide range of machining applications tungsten carbide is used as tool inserts material. Tungsten carbide is highly suitable for very difficult to cut materials, alloys of aluminium-silicon, cast iron, and metal-matrix composites (Köpf et al., 2001). Diamond is known for its highest hardness among all the naturally known and available materials, but it also has plenty of other properties like Chemical inertness, low coefficient of friction, high resistance to the wear, along with high thermal conductivity. Because of all these properties diamond has been the center of attraction for cutting tools for the application in machining industries. The most commonly used material in machining industry for cutting tool is tungsten carbide (WC) (Jeyapandiarajan and Xavior, 2019, Rana et al., 2021).

Diamonds have unique set of properties which makes it ideal for protective coating on the cutting tools (Gäbler et al., 2000). The majority used cutting tool substrate material in the machining of plastics, aluminium composite and fiberglass is Tungsten Carbide (WC) (Dai et al., 2000, Ullen et al., 2020). Deposition of thin polycrystalline diamond films on WC tool insets would significantly improve the various properties viz. wear resistance, tool life, cutting performance and precision machining and will reduce machining cost, (Kuo et al., 1996, Endler et al., 1999).

Chemical Vapour Deposition (CVD) is the most commonly used approach for depositing the diamond coatings directly onto the substrates (Hintermann, 1996, Mallika and Komanduri, 1999). An effective and efficient way for improving the physical properties of tungsten carbide substrate $\mathrm{WC}+6 \mathrm{wt} \% \mathrm{Co}$ (WC6) is to coat it with diamond surface layers using Chemical vapour deposition (CVD). Occasional poor adhesion of coating to the selected substrate 
material and the development of cracks within either the interface or the coating, has always been the major obstacle while tapping the full potential of the chemical, mechanical and tribological properties of CVD diamond layers. Although the graphitization situated at the interface is induced by the binder phase Co which, has been the major reason behind the terrible untimely failure of adhesion of the developed diamond coatings on carbide tools (Chen and Narayan, 1993). Well defined compressive stresses compensate external thermal and mechanical loads during the service, which forestall the generation and propagation of cracks in the deposited diamond coatings. But then, the film delamination will occur if the compressive internal stresses become high (Nesladek et al., 1995, Gunnars and Alahelisten, 1996]. As mentioned by researchers, the chemical vapour deposition (CVD) method is used to produce diamond film coatings (DC) on the selected tungsten carbide substrate to increases the wear resistance as well as durability of the carbide tools. It also significantly reduces the coefficient of friction between the coated tool and produced chips. Also, DC prevents corrosion and erosion of tool, reduces the built-up edges as well as the heat produced, while improving the treated surface's quality (Dumpala et al., 2015). This is true, in the field of defense and aerospace applications, where high-precision processing of materials is used. Formation of two or multilayered DCs achieves the increase in the adhesion of the coating to the substrate while improving the cutting properties of the tool.

Previous researchers described the deposition of a nanocrystalline diamond layer from above (Catledge et al., 2000, Sun et al., 2009, Dumpala, et al., 2014), while writing on the properties and deposition of the two-layer micro/ nanocrystalline composite diamond coatings, with this coating configuration, high elasticity and low roughness of nanocrystalline diamond layers can be used together with the good adhesion to the selected substrate material and high hardness of microcrystalline diamond layers (Dumpala et al., 2015). To increase the thermal conductivity and prevent the cracking one can use multilayer DCs additionally (Schäfer et al., 2006).

In the present work, we demonstrate a fresh approach to develop the polycrystalline diamond films on the WC tools inserts. The polycrystalline diamond films are of high adhesion and crystallinity. Good adhesion and crystallinity make these materials more suitable for the machine industry.

\section{EXPERIMENTAL}

In the present work, tungsten carbide tools were coated with polycrystalline diamond films at atmospheric pressure using thermal chemical vapor deposition method. The substrates were cleaned prior to diamond deposition and then loaded in the thermal CVD system. The experiment was carried out at atmospheric pressure and $\sim 900^{\circ} \mathrm{C}$ in the thermal CVD. Sugarcane bagasse was used as a carbon precursor for the growth of diamond on WC substrates with a mixture of $\mathrm{Ar} / \mathrm{H} 2$ to carry the effluent gases. The rich gas phase chemistry of the effluent gases produced by pyrolysis of sugarcane bagasse as mentioned in (Krishnia and Tyagi, 2018, Krishnia et al., 2018) is responsible for diamond growth. The morphology of both bare and after diamond growth WC substrates was studied using scanning electron microscope (Hitachi TM3000). The diamond growth was also confirmed by capturing the Raman spectra using Micro-Raman spectrometer Renishaw via model $(514 \mathrm{~nm})$. The micro-hardness of the samples was evaluated using indentation method by using Fischerscope HM2000s (Lal and Singh, 2018, Bansal et al., 2021).

\section{RESULTS AND DISCUSSION}

The morphology of the polycrystalline diamond films on WC tools inserts was determined using Scanning Electron Microscopy (SEM). The SEM micrographs were captured at different locations and magnifications as shown in Figure 1 (b \& c). The quality of the films on the overall tool surface is almost same and the areas of highly crystalline quality with faceted growth have been shown in inset of Figure 1 (b) inset. It is clearly evident from Figure 1(a) that there absence of any faceted structure on the surface of the bare WC tool insert whereas this faceted growth can be seen in Figure $1(\mathrm{~b} \& \mathrm{c})$. 

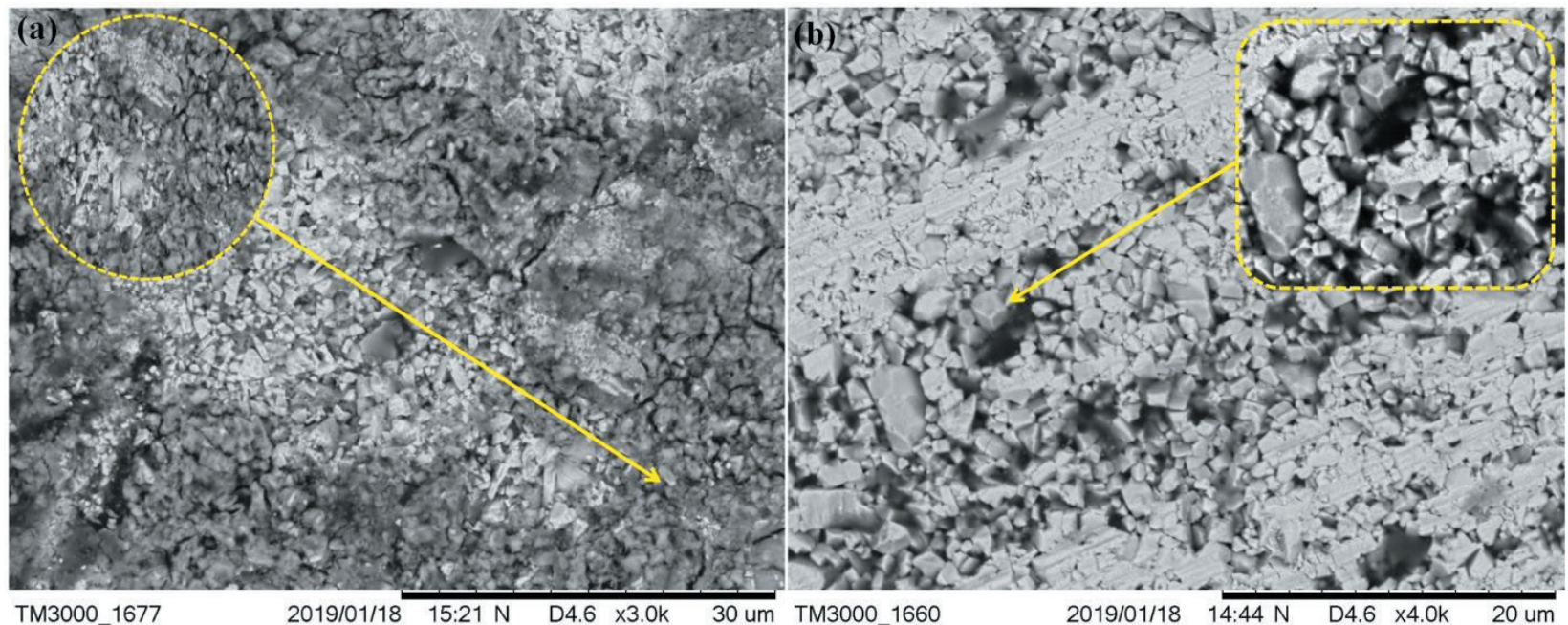

TM3000_1677

2019/01/18 15:21 N D4.6 x3.0k 30 um TM3000_1660

$2019 / 01 / 18 \quad 14: 44 \mathrm{~N}$

20 um

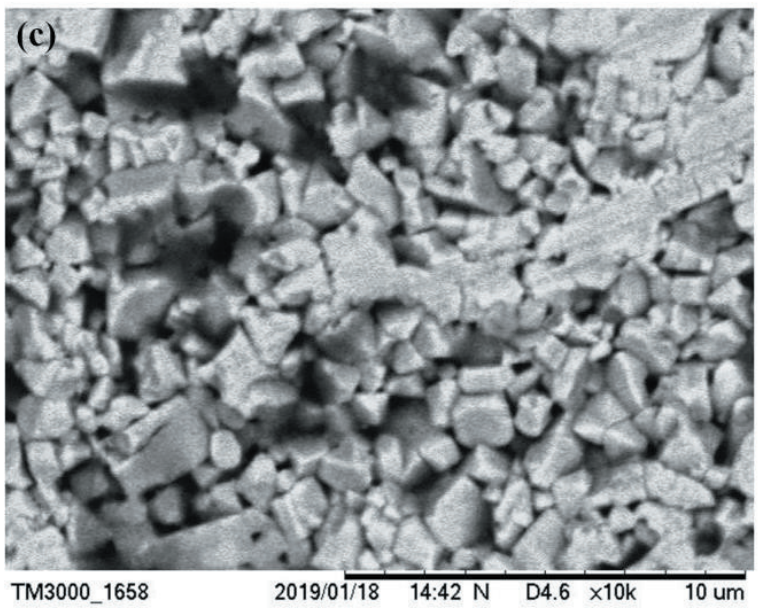

Figure 1. (a) Bare WC tool inert, the inset shows the absence of any faceted structure before diamond deposition, (b \& c) diamond coated WC tool inserts where a clear faceted growth on surface can be seen.

Raman spectroscopy was used to investigate the quality of the diamond coatings. Figure 2 shows the Raman spectrum of the diamond coated WC tool insert. The D and G band lies at 1338 and $1576 \mathrm{~cm}-1$ respectively. After deconvolution it has been found that the sp3 content in the films is more and ID/IG is found to be 1.11 . The blue shift of the $\mathrm{D}$ band from its signature position i.e. $1332 \mathrm{~cm}-1$ of natural diamond may be due to the compressive stress in the coating (Sein et al., 2003, Tang et al., 2001, Krishnia and Tyagi, 2018, Krishnia et al. 2018) which arises as a result of the tool geometry as well as mismatch in thermal coefficients of both diamond and tungsten carbide. 


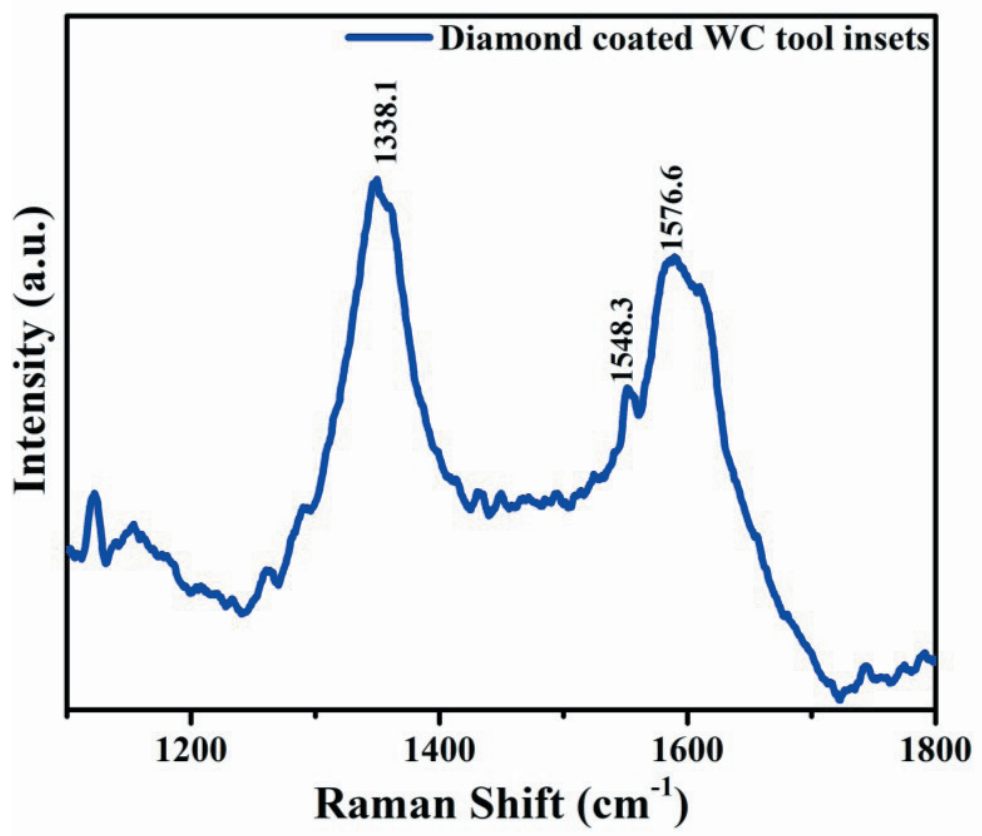

Figure 2 Raman spectra of diamond coated WC tool inserts

The micro-hardness testing has been done using indentation. During indentation the indenter (diamond coated/ uncoated tool) is allowed to indent into the surface and the surface profile after indentation is measured so as to test hardness. The indentation test allows the evaluation of the diamond coating film adhesion on the WC substrate surface (Polini et al., 2000). The Vickers Hardness evaluated after the indentation is shown in Figure 3: and the values are found to be 1103.1 and $1423.32 \mathrm{HV}$ for both un-coated and diamond coated tool respectively. The loading and unloading profile diagrams obtained during the indentation testing with the indentation mechanism is shown in Figure 4 (a-c).

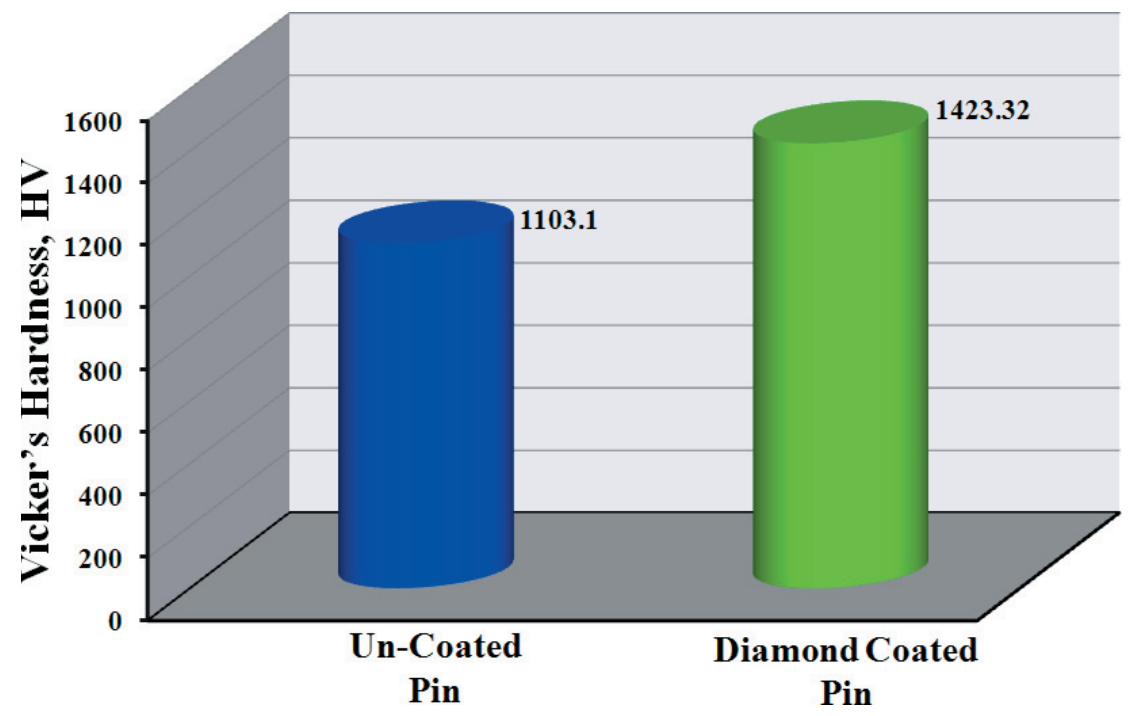

Figure 3 Vickers hardness values of uncoated and diamond coated WC tool inserts. 


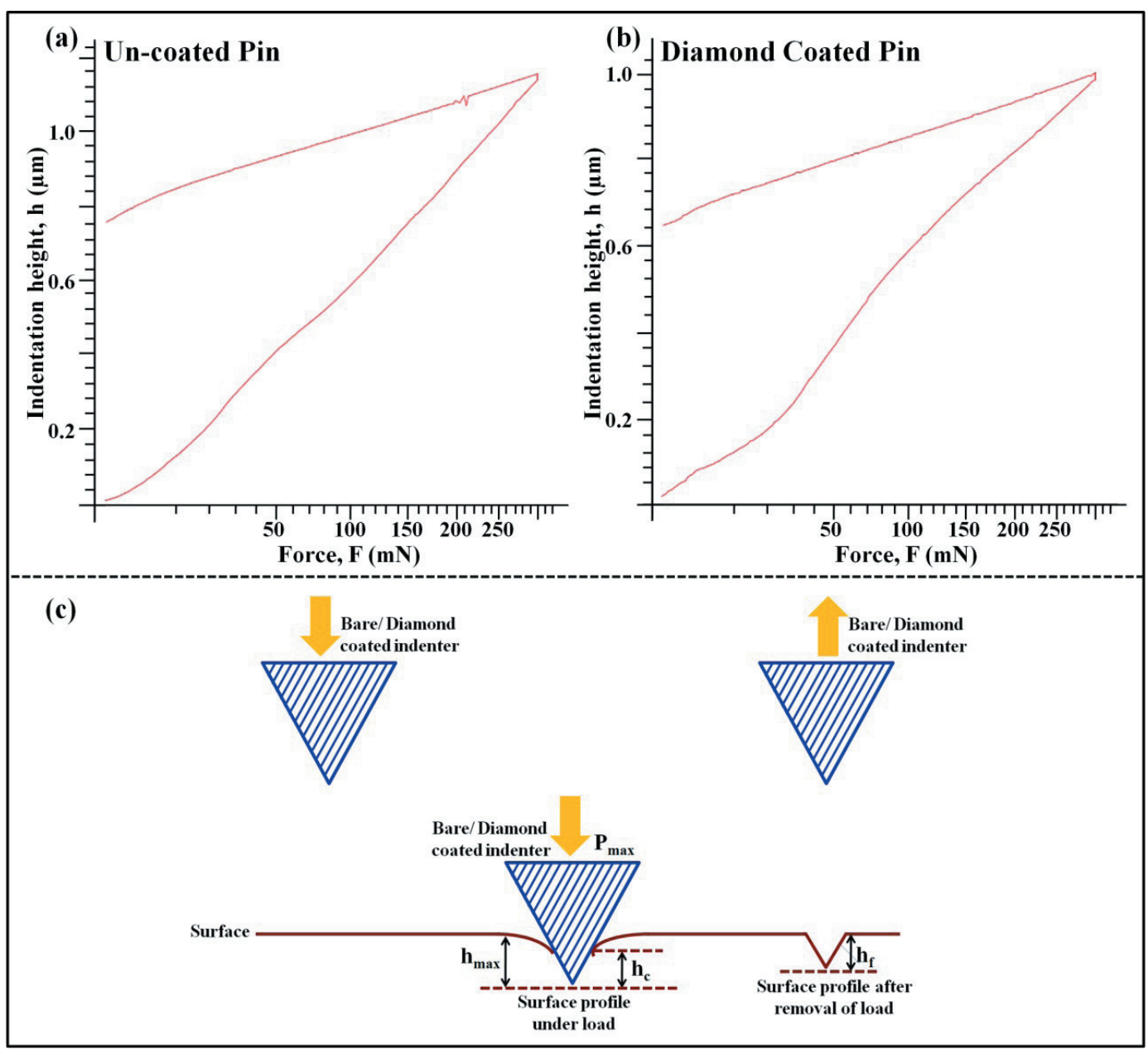

Figure 4 Loading and unloading profile diagrams for (a) uncoated and (b) diamond coated pins with (c) indentation mechanism for micro-hardness testing.

\section{CONCLUSION}

In this study, we have coated the WC tool inserts with diamond using thermal-CVD system. The coating has been achieved by using sugarcane bagasse. The surface morphological studies reveal growth of very good quality and crystallinity diamond films. The thicker and good quality of diamond coating over the tool surface is supposed to give the tool inserts better tool life as well as better machining quality. The Vickers hardness of the tool inserts is found to be $1423.32 \mathrm{HV}$ for diamond coated tool inserts which is $29 \%$ better than the un-coated tools.

\section{ACKNOWLEDGEMENT}

Authors would like to acknowledge the support of Nano Research Facility of Indian Institute Technology, Delhi, India and Institute Instrumentation Centre of Indian Institute Technology, Roorkee, India for allowing us to use their facilities for material characterization. Authors also extend their regards to thank Centre for Advanced Production and Industrial Engineering Research (CAPIER) of Delhi Technological University, New Delhi, India, for providing the facilities for the completion of this work. 


\section{REFERENCES}

Bansal S., Saraf A., Rana R. and Lal R., 2021. Effect of Picosecond Laser Texture Surface on Tribological Properties on High-Chromium Steel Under Non-lubricated Conditions. Advances in Manufacturing and Industrial Engineering, pp. 257-267. Springer, Singapore.

Catledge, S.A., Baker, P., Tarvin, J.T. and Vohra, Y.K., 2000. Multilayer nanocrystalline / microcrystalline diamond films studied by laser reflectance interferometry. Diamond and related materials, 9(8), pp.1512-1517.

Chen, X. and Narayan, J., 1993. Effect of the chemical nature of transition metal substrates on chemical vapor deposition of diamond. Journal of applied physics, 74(6), pp.4168-4173.

Dai, M., Zhou, K., Yuan, Z., Ding, Q. and Fu, Z., 2000. The cutting performance of diamond and DLC-coated cutting tools. Diamond and Related Materials, 9(9-10), pp.1753-1757.

Dumpala, R., Chandran, M. and Rao, M.R., 2015. Engineered CVD diamond coatings for machining and tribological applications. Jom, 67(7), pp.1565-1577.

Dumpala, R., Kumar, N., Kumaran, C.R., Dash, S., Ramamoorthy, B. and Rao, M.R., 2014. Adhesion characteristics of nano-and micro-crystalline diamond coatings: Raman stress mapping of the scratch tracks. Diamond and related materials, 44 , pp.71-77.

Endler, I., Bartsch, K., Leonhardt, A., Scheibe, H.J., Ziegele, H., Fuchs, I. and Raatz, C., 1999. Preparation and wear behaviour of woodworking tools coated with superhard layers. Diamond and Related Materials, 8(2-5), pp.834-839.

Gäbler, J., Schäfer, L. and Westermann, H., 2000. Chemical vapour deposition diamond coated microtools for grinding, milling and drilling. Diamond and related materials, 9(3-6), pp.921-924.

Gunnars, J. and Alahelisten, A., 1996. Thermal stresses in diamond coatings and their influence on coating wear and failure. Surface and Coatings Technology, 80(3), pp.303-312.

Hintermann, H.E., 1996. Advances and development in CVD technology. Materials Science and Engineering: A, 209(1-2), pp.366-371.

Jeyapandiarajan, P. and Xavior, A., 2019. Influence of cutting condition on machinability aspects of Inconel 718. Journal of Engineering Research, 7(2): 315-332.

Köpf, A., Lux, B. and Haubner, R., 2001. Substrate Effects during Nucleation. New Diamond and Frontier Carbon Technology, 11(1).

Krishnia, L. and Tyagi, P.K., 2018. Growth and characterization of polycrystalline diamond films on silicon using sugarcane bagasse as carbon precursor at atmospheric pressure by thermal chemical vapor deposition. Diamond and Related Materials, 87, pp.18-26.

Krishnia, L., Yadav, B.S., Palnitkar, U., Satyam, P.V., Gupta, B.K., Koratkar, N.A. and Tyagi, P.K., 2018. Aspyrolyzed sugarcane bagasse possessing exotic field emission properties. Applied Surface Science, 443, pp.184190.

Kuo, C.T., Lin, C.R. and Lien, H.M., 1996. Origins of the residual stress in CVD diamond films. Thin Solid Films, 290, pp.254-259.

Lal, R. and Singh, R.C., 2018. Experimental comparative study of chrome steel pin with and without chrome plated cast iron disc in situ fully flooded interface lubrication. Surface Topography: Metrology and Properties, 6(3): 035001 . 
Mallika, K. and Komanduri, R., 1999. Diamond coatings on cemented tungsten carbide tools by low-pressure microwave CVD. Wear, 224(2), pp.245-266.

Nesladek, M., Vandierendonck, K., Quaeyhaegens, C., Kerkhofs, M. and Stals, L.M., 1995. Adhesion of diamond coatings on cemented carbides. Thin Solid Films, 270(1-2), pp.184-188.

Polini, R., D'antonio, P., Casto, S.L., Ruisi, V.F. and Traversa, E., 2000. Cutting performance and indentation behaviour of diamond films on Co-cemented tungsten carbide. Surface and Coatings Technology, 123(1), pp.7883.

Rana, R., Murtaza, Q. and Walia, R.S., 2021. Optimization using genetic algorithm of tribological behaviour of WC tool material. Indian Journal of Engineering and Materials Sciences (IJEMS), 27(4): 889-896.

Schäfer, L., Höfer, M. and Kröger, R., 2006. The versatility of hot-filament activated chemical vapor deposition. Thin Solid Films, 515(3), pp.1017-1024.

Sein, H., Ahmed, W., Jackson, M., Ali, N. and Gracio, J., 2003. Stress distribution in diamond films grown on cemented WC-Co dental burs using modified hot-filament CVD. Surface and Coatings Technology, 163, pp.196-202.

Sun, F., Ma, Y., Shen, B., Zhang, Z. and Chen, M., 2009. Fabrication and application of nano-microcrystalline composite diamond films on the interior hole surfaces of Co cemented tungsten carbide substrates. Diamond and Related Materials, 18(2-3), pp.276-282.

Tang, W., Wang, Q., Wang, S. and Lu, F., 2001. Adherent diamond coatings on cemented carbide substrates with different cobalt contents. Diamond and related materials, 10(9-10), pp.1700-1704.

Ullen, N.B., Hasak, S.M.A. and Dirikolu, M.H., 2020. Factors influencing the machinability during turning sinter-hardened Cu-Ni-Mo based steel: Dependency on cutting speed, feed rate and cutting depth. Journal of Engineering Research, 8(4): 236-257. 